UDK: $821.134(7 / 8) .09$

821.134.2(866).09-31 Охеда М.

821.134.2(82).09-31 Аира С. DOI: https://doi.org/10.18485/legado_hispanico.2020.ch16

\author{
Giuseppe Gatti Riccardi ${ }^{1}$ \\ Università degli Studi Guglielmo Marconi - Roma \\ Italia
}

\title{
FORMAS DE INVISIBILIDAD EN DOS NOVELAS \\ HISPANOAMERICANAS DE COMIENZOS \\ DEL NUEVO SIGLO. TRANSPARENCIAS \\ AUTOELEGIDAS, CYBER-MONSTRUOS Y \\ HOLOGRAMAS CORPÓREOS EN MÓNICA \\ OJEDA Y CÉSAR AIRA
}

\begin{abstract}
Resumen
El propósito del presente ensayo reside en estudiar de qué manera algunos rasgos idiosincrásicos de la vida contemporánea (el debilitamiento de las pulsiones humanas positivas, la consolidación de las energías violentas de repulsión y hostilidad hacia el Otro, el rechazo de los sistemas sociopolíticos, etc.) se trasladan al ámbito literario en dos textos de ficción escritos en los primeros ańos del siglo XXI. Sobre la base de reflexiones de teóricos como Jean Baudrillard, Marcel Schwob o Jean Franco, entre otros, se intenta analizar tanto la relación que se establece entre la liberación de la energía vital presente en el ser humano y el ejercicio del mal, como la manera en que la ficción contemporánea expresa esta contaminación. Objeto de estudio son novelas breves: Nefando (2017), de la escritora ecuatoriana Mónica Ojeda, y El mago (2002), del argentino César

\footnotetext{
${ }^{1}$ giuseppe_gatti@hotmail.com
} 
Aira. Nuestro análisis trata de poner de relieve la presencia - en ambos textosde dos tendencias características de la producción literaria hispanoamericana más reciente: por un lado, se subraya el vínculo entre las manifestaciones de violencia extrema y un cierto tipo de textos de ficción que adoptan estructuras fragmentarias, incluyen imágenes o dibujos en los textos, muestran lo más sórdido y malvado de la interacción entre seres humanos (Ojeda). Por otro lado, se tratará de demostrar cómo ciertos productos literarios logran expresar las alteraciones de lo real en función de lo mágico, y se centran en la representación de estados de alienación del sujeto con respecto a su propia subjetividad (Aira).

Palabras clave: Narrativa hispanoamericana contemporánea, Mónica Ojeda, César Aira, Nefando, El mago.

Una noche en el circo recobré un lenguaje perdido en el momento que los jinetes con antorchas en la mano galopaban en ronda feroz sobre corceles negros. Ni en mis sueńos de dicha existirá un coro de ángeles que suministre algo semejante a los sonidos calientes para mi corazón de los cascos contra las arenas. (Alejandra Pizarnik, La extracción de la piedra de la locura)

\section{El marco teórico: peligros de la red y poderes sobrenaturales}

En la época contemporánea, y en particular en los últimos veinte años, el funcionamiento de las estructuras sociales, políticas y económicas basado en la creación de circuitos homogéneos y en un sistema que quiere imponer modelos consensuales, positivos y performantes parece representar el principal factor desencadenante del rechazo que el ser humano plantea hacia ese mundo sincrónico en el que la velocidad es maravillosa. El resultado de este rechazo se manifiesta en una suerte de rebelión que ya no es la revuelta crítica, embebida de ideologías, de los años sesenta y setenta, sino una forma de reacción más compleja de la que surgen las manifestaciones más características de nuestra era: la difusión urbi et orbi del terrorismo, el aumento en el consumo de drogas, la afirmación de patologías virales (vinculadas tanto con la vida humana como con la de los sistemas informáticos), la extensión de las áreas de inseguridad social y hasta fenómenos aún más sofisticados y ya muy estudiados como el culto a la producción y al consumo, la compulsión hacia la posesión de bienes y, en el ámbito artístico, la celebración de todo tipo de performance que elimina la duración de la obra de arte misma. 
En el plano social, las grandes masas han tenido históricamente el problema irresuelto de la imposibilidad de poner de acuerdo a todos sus elementos con respecto a la consecución de un determinado resultado de interés común: la imposibilidad de que todos sus miembros coincidan en tiempos y formas en alcanzar el mismo objetivo ha complicado, a lo largo de la historia, la manifestación de la voluntad crítica de las masas y ha hecho posible que sus integrantes sólo fueran capaces de expresar un poder indiferenciado que se refleja, en el plano concreto, en las distintas formas de rechazo de lo establecido. Esto significa que la negación se convierte en una de las herramientas de base de las masas, que rechaza y refuta de forma indiscriminada todo tipo de proyecto social, económico o político que la supere y que trascienda su dimensión. Jean Baudrillard define este rechazo como una forma de alergia y sostiene que

la homogeneización de los circuitos, el universo ideal de la síntesis y de la prótesis, el universo positivo, consensual, sincrónico y performant constituyen un mundo inaceptable. No sólo el cuerpo se rebela [...] sino que la propia mente se rebela contra la sinergía que se le impone con innumerables formas de alergia. [...] El rechazo, la alergia son formas de energía singular. De esta energía visceral, que ha ocupado el lugar de la negatividad y de la revuelta crítica, nacen los fenómenos más originales de nuestro tiempo [...]. Las mismas catástrofes naturales parecen una forma de alergia, de rechazo por la naturaleza de una influencia operacional de lo humano. Allí donde la negatividad muere, constituyen un signo irreductible de violencia, un signo preciso y sobrenatural de denegación (Baudrillard 1999: 79).

La virulencia de las catástrofes naturales, entendidas como una reacción alérgica de nuestro planeta a la acción humana, establece un diálogo alegórico con el desorden social, como en un proceso de contaminación que une lo natural a lo social-humano, en un mundo cada vez más acelerado y más ebrio. Esta estructura social ultrarrápida se caracteriza por la reducción o la completa elisión de las distancias y por la aniquilación de los espacios intermedios en pos de la consecución inmediata de la meta final, lo cual genera un estado de tránsito permanente para el ser humano, modificando a su vez el funcionamiento social. Los impulsos positivos que albergan en el sujeto se han apaciguado, las elecciones fundadas en las grandes pulsiones parecen haber desaparecido, los deseos se hacen débiles y los gustos y las preferencias de los individuos van haciéndose cada vez más difuminados y menos determinados. El efecto de tales procesos consiste en una reducción del 
peso de la voluntad íntima y de los anhelos individuales, frente a cuyo derrumbe se han fortalecido los sentimientos de rechazo y de hostilidad, que suelen ser más intensos:

Ya sólo deseamos débilmente, nuestros gustos están cada vez menos determinados. Tanto las constelaciones del gusto, del deseo, como las de la voluntad, se han deshecho gracias a algún efecto misterioso. En cambio, las de la mala voluntad, la repulsión y la repugnancia se han reforzado. Diríase que de ahí viene una energía nueva, una energía inversa, una fuerza que nos hace las veces del deseo, una abreacción vital que nos hace las veces del mundo, del cuerpo, del sexo. [...]. Sólo los rechazos son violentos, los proyectos ya no lo son (Baudrillard 1999: 80).

Una de las consecuencias del debilitamiento de las pulsiones positivas (voluntad, gusto, etc.) y de la consolidación de las energías violentas (repulsión, rechazo, hostilidad) se refleja, tanto en el plano individual como en el colectivo, en el hecho de que las actividades humanas van a estar cada vez más influenciadas por una suerte de disgusto íntimo del propio «yo», como si el ser humano intentara liberarse de su propia energía comprimida, y como si no hubiese más una verdadera voluntad de acción sino una repugnancia continua por el sistema que se expresa precisamente en la violencia. En la edad contemporánea, las acciones individuales proceden «de una secreta desherencia que nos lleva a liberarnos de nuestra energía de cualquier manera, y son por tanto una forma de exorcismo más que de voluntad de acción. ¿Se tratara de una nueva forma del principio del mal, no lejos de la magia, cuyo epicentro, como sabemos, es precisamente el exorcismo?» (Baudrillard 1999: 80). Sobre la base de estas reflexiones, que conjugan la violencia al elemento mágico y ponen en relación la liberación de la energía vital con el ejercicio del mal, el objeto de nuestro estudio consiste en el análisis de dos textos de ficción publicados en los primeros años de la nueva centuria en el marco de una cierta vertiente de la producción literaria hispanoamericana relacionada, respectivamente, con las manifestaciones de violencia extrema y las alteraciones de lo real en función de lo mágico. En cuanto a su adscripción genérica, en ambos casos se trata de dos novela breves: Nefando (2017), de la escritora ecuatoriana Mónica Ojeda (1988), y El mago, que el argentino César Aira (1949) publicó en su país en 2002.

Los textos de ficción elegidos nos parecen representativos de dos de las corrientes principales que se vislumbran en la nueva narrativa en español en este comienzo del nuevo siglo: Mónica Ojeda se colocaría, en nuestra opinión, en el marco de aquellos escritores cuyos textos de ficción 
mezclan tratos líricos y realismo crudo, y no desdeñan la adopción de estructuras fragmentarias ni la inclusión de imágenes o dibujos en los textos. Se trata de obras literarias

con propensión a la fractalidad, excursos y digresiones de raigambre bolañesca y wallaciana, pero asimismo practicantes de un fraseo tan contundente como [...] cargados de lirismo; apuestan frecuentemente por el reclamo visual, con inclusión de imágenes o recursos ekfrásticos en el cuerpo de la obra, dialogan con el lector y renuncian a establecer límites entre ciencias duras y blandas (Noguerol Jiménez 2018: 124).

Por su parte, frente al vértigo de una escritura histérica en que todos los personajes acaban interconectados entre sí, César Aira podría colocarse en el marco de aquellos escritores que no deben considerarse necesariamente enfrentados al primer grupo, pero que cultivan una escritura más alejada de las presiones mediáticas y tecnológicas, centrándose en la creación de textos más pausados y más apartados «del ruido blanco que condiciona nuestra cotidianeidad, a través del elogio del detalle, el intersticio y la lentitud, de la repetición y la espacialización, de la actitud del post-flaneur y la sensualización de las experiencias» (Noguerol Jiménez 2018: 124). En la novela de Mónica Ojeda la fractalidad surge de la estructura misma del texto ${ }^{2}$ : el escenario de la representación es un piso de estudiantes ubicado en Barcelona, en el que se entrecruzan las vivencias de seis jóvenes cuyas historias se narran en apartados textuales autónomos y cuyas experiencias vitales se encuentran en el límite fronterizo que separa el espacio de la moralidad del abismo de lo monstruoso. Tres de ellos, los hermanos Terán, crean un videojuego en línea en cuyo contenido se mezclan la violencia extrema y el abuso de menores (que ellos mismos han padecido). El juego está destinado a

\footnotetext{
${ }^{2}$ Mónica Ojeda Franco nace en Guayaquil en 1988 y a pesar de su todavía joven edad ya es considerada como una de las novelistas de mayor proyección de la literatura hispanoamericana contemporánea. Su primera novela, La desfiguración Silva, se publica en 2014 y se hace merecedora del Premio ALBA de Narrativa. Nefando, el texto de ficción que será objeto de nuestro estudio en las páginas que siguen, es su segunda novela: la obra obtuvo en 2015 una mención de honor del «Premio de novela corta Miguel Donoso Pareja». En enero de 2018 Ojeda publica su tercera novela, Mandíbula, la última hasta la fecha actual. La autora frecuenta también el género del cuento: en 2017 da a la imprenta un volumen de relatos titulado Caninos. Finalmente, en lo que se refiere a la producción poética de nuestra autora, en 2015 ve la luz la recopilación de poemas titulada El ciclo de las piedras. Su trayectoria literaria ha sido tan destacada que en 2017 ha sido incluida en la lista Bogotá 39-2017 como una de los 39 mejores escritores del panorama latinoamericano por debajo de los 40 años de edad.
} 
los frecuentadores de la deep web y su nombre, Nefando, da el título a la novela: la acción del juego interactivo, muy reducida y difícil de descifrar en su escaso desarrollo, transcurre en una habitación cerrada, y parece estar basada en reminiscencias de la violencia física y los atropellos sexuales que los tres jóvenes creadores (dos hermanas y un hermano) habían sufrido en su infancia por parte de un padre abusador y de una madre cómplice silenciosa.

Ojeda logra hacer confluir en su texto los elementos más marcados del carácter psicótico del ser humano de la contemporaneidad: a lo largo del hilo narrativo, la autora reúne y describe «las fenomenologías pop y las mitologías-basura del marketing globalizado, indica y reivindica la violencia y la pornografía como elementos primarios y constitutivos de los actuales esquemas mentales del mundo. [De ahí] la confirmación extrema de que la realidad es de por sí psicopatológica, irremediablemente marcada por una locura que lo pervade todo» (Palladini 2008: 160) ${ }^{3}$. La violencia y la pornografía como elementos primarios de los esquemas de la sociedad actual representan un rasgo constitutivo de la trama: paralelamente a la actividad de creación de un videojuego siniestro y morboso como Nefando, en la habitación que linda con la de los tres hermanos, una joven becaria, Kiki Ortega, intenta redactar una novela pornoerótica protagonizada por tres preadolescentes de inclinaciones sádicas. Unos metros más allá, del otro lado de la pared, el joven Iván Herrera, reniega de su propia sexualidad y llega hasta a castigar físicamente su propio cuerpo hacia el que siente rechazo. La autora obliga al lector a enfrentarse al desarrollo de actividades o pensamientos que el juicio social compartido suele atribuir a individuos abyectos y monstruosos y lo consigue a través de una estructura narrativa que induce al destinatario del relato a colocar dentro de lo humano las aparentes desviaciones de los personajes de ficción. La estructura argumentativa del texto, en suma, induce a reconocer que «lo deleznable, lo abyecto no es menos humano que todo lo demás. Y es justamente el carácter oscuro de la humanidad lo que actúa como nexo inexorable entre todos los mortales» (López 2016).

En Nefando todas las figuras de ficción conviven, cada cual con sus peculiaridades, con la dimensión tanática: hombres y mujeres del relato

\footnotetext{
${ }^{3}$ Así el texto de Palladini en el original, en que el sociólogo italiano habla de las «fenomenologie pop e le mitologie-spazzatura del marketing globalizzato, indica e rivendica la violenza e la pornografia come elementi primari e costitutivi degli attuali schemi mentali del mondo» y reflexiona sobre «la conferma estrema che la realtà è di per sé psicopatologica, irrimediabilmente segnata da una pazzia omnipervasiva» [la traducción es mía].
} 
están permanentemente conectados con una suerte de pulsión hacia la desaparición, hacia la (auto)aniquilación, como si hubieran aprendido a compartir su espacio-tiempo vital con la idea del fin. El lector se enfrenta a un texto en el que los personajes se comunican con la muerte: todos dan la sensación de estar interactuando con ella, hasta evocar la impresión de que el contacto con la idea de aniquilamiento sea parte integrante de su propio ser, según un esquema por el que la muerte, «considerada como idea y como algo real, se instala primero en el cerebro y desde ahí comienza a descender, sin apuro, por la escalera de los huesos, hasta conquistar el cuerpo. Uno empieza a morirse en el instante exacto en que piensa por primera vez que va a morirse» (Fresán 2017: 139).

En cuanto a las formas de representación de la invisibilidad en $E l$ mago, importa en primer lugar subrayar cómo la obra establece un diálogo con otro de los textos narrativos breves de César Aira, la novela Varamo $(2002)^{4}$ : ambas se caracterizan por una reflexión de fondo que -a partir de una construcción temática en apariencia lúdica- se centra en el motivo de la consolidación de la identidad del individuo y en la dificultad del ser humano para darle consistencia a su propio «yo». En ambas novelas el escritor argentino logra combinar

una trama disparatada a la que no es ajena la idea del juego, y una reflexión sobre el hecho de narrar, sobre sus posibilidades y límites. Protagonizadas por un par de aprendices de la vida, estos héroes de medio pelo son dos magníficos ceros. Los avatares que definen a ambos tienen que ver con el

\footnotetext{
${ }^{4}$ César Aira (1949) es un escritor sumamente prolífico que ha llegado a publicar más de cien obras de ficción, a partir de la década del setenta (en el período comprendido entre 1975 y 1983, es decir, todavía en la etapa de la dictadura militar, Aira publica tres novelas: Moreira, 1975; Ema, la cautiva, 1977; La luz argentina, 1983). En su extensa producción el género que predomina es el de la narrativa breve: el mismo autor define sus novelas cortas como «cuentos de hadas dadaístas». Ante la imposibilidad de indicar aquí todos los títulos de ficción del autor, nos limitamos a centrar la atención en el período comprendido entre el año 2000 y el año 2005, en el que se gesta la escritura de la novela que se analiza en estas páginas: El mago, publicada por primera vez en el año 2002. En el año 2000 Aira pública El juego de los mundos y Un episodio en la vida del pintor viajero. En 2001 ven la luz Un sueño realizado y La villa. En el mismo año en que se publica El mago, salen también Varamo y La pastilla de hormona. El año siguiente son tres los textos de ficción que salen de la imprenta: La princesa Primavera, Mil gotas y El tilo. En 2004 se publican Las noches de Flores y Yo era una chica moderna. Finalmente, en el año 2005 ven la luz cuatro textos: Yo era una niña de siete años, El cerebro musical, El pequeño monje budista, Cómo me reí. La trayectoria creativa de Aira sigue con la misma intensidad en los años siguientes, extendiéndose mucho más allá de nuestro escueto y nada exhaustivo resumen; ejemplo de su prolífica actividad literaria son las tres breves novelas que publica en el año 2018, sus últimas creaciones hasta la fecha: El gran misterio, Un filósofo y Prins.
} 
problema de su identidad personal, con esa aleatoriedad de su conciencia que no se estructura en un yo orgánico y concluso (Doncel 2002).

En El mago, en particular, las elucubraciones acerca de la aleatoriedad de la conciencia y de los obstáculos que el ser humano encuentra para estructurar orgánicamente su propia individualidad se apoyan en el elemento mágico, que aparece en el texto en forma irónica y al mismo tiempo inquietante. La figura alrededor de la cual se construye el hilo narrativo es Pedro María Gregorini, mago argentino conocido en su ámbito artístico como Hans Chans, que participa en un congreso internacional de magia en Panamá: a través del relato de las peripecias de Hans, el autor plantea una reflexión sobre las potencialidades de trasgresión de las normas sociales, de los límites humanos y de transformación del mundo que residen en lo mágico. El mago argentino, una vez llegado a la ciudad del Istmo, se abisma en una «dimensión difusa» que lo obliga -y obliga al lector- a cavilar sobre la capacidad de la magia verdadera (pues él tiene poderes mágicos: no es un simple ilusionista) para perturbar las lógicas de sentido ligadas a la razón. De este modo, el relato se construye no sólo como una reflexión introspectiva ininterrumpida acerca de los límites fronterizos que separan la ficción de lo real, sino también como una meditación del propio Aira sobre cómo descifrar los modelos culturales del presente: «lo mágico interviene en el presente de la ficción y, atravesándola, en el presente de la escritura, como un principio de revolución textual: un principio de catástrofe de los modos de entender y de los sistemas de legibilidad en que se alían un discurso letrado y un régimen de dominio asociado al logos occidental» (Prieto 2016: 153). Lo que más importa para nuestro enfoque es que la novela de Aira puede interpretarse como un texto caracterizado por la pervivencia conflictiva de un sentimiento auténtico de lo mágico que induce a suponer una dimensión utópica: es decir, se vislumbra la posibilidad para el mago de desplegar un movimiento de «reimaginación del presente». Esta dinámica de reimaginación apunta, al menos en las intenciones del hombre, a la consecución para él de mejoras tanto desde el punto de vista profesional como de las relaciones intersubjetivas y de la emancipación existencial.

Finalmente, antes de emprender nuestro estudio de los dos textos de una forma más pormenorizada, cabría reflexionar sobre diferencias y parecidos que se encuentran al analizar los escenarios en que se desarrollan las tramas de las dos novelas. En este sentido, importa subrayar la presencia, en ambas obras, de un proceso común 
de resemantización del espacio con respecto al carácter amenazante que éste suele adquirir en las historias tradicionales de fantasmas o de magia. En ambos textos, el marco escénico tiene una textura que genera un profundo desacomodo anímico en los personajes de la ficción, pero este efecto se logra renunciando a las ambientaciones lóbregas y oscuras típicas de las Ghost stories del siglo XIX y de la primera mitad del siglo $\mathrm{XX}$; los ambientes ya no coinciden, en suma, con «la morada negra como espejo del locus infernal» (Negroni 2009: 11) que se representa en los relatos de horror y en las galerías fantásticas de la tradición consolidada.

Nefando, en particular, es una novela que se desarrolla casi sólo en espacios cerrados: a menudo se trata de las tres habitaciones del piso barcelonés que comparten los protagonistas, es decir, ambientes de dimensiones reducidas y, por lo general, oscuros y descuidados. Sin embargo, lo que es más relevante para nuestro análisis es el proceso de animalización que padecen los espacios físicos, como efecto de una percepción distorsionada por parte del personaje-observador. Esta distorsión perceptiva ocurre, en particular, en el caso del personaje de Kiki, encerrada casi sin solución de continuidad en su habitación con el propósito de escribir su novela pornoerótica: «Deslizó la mano sobre la pared y, cuando notó los relieves y la aspereza del muro despellejado, imaginó el lomo de un cocodrilo y supo que sólo se podía escribir una novela así: rodeada de escamas» (Ojeda 2016: 13). Poco después, la sensación de estar viviendo en un espacio animalizado se vuelve a presentar, cuando el mismo personaje siente que el cuarto en el que vive se convierte en un reptil que la encierra y la mantiene cautiva, sin permitirle siquiera darse cuenta de si es capaz de pronunciar unas palabras «La habitación era un refugio-reptil-muro donde resonaba su voz indiferente a otras miles de voces, donde su voz apagaba a las demás de un solo soplo, donde era sorda y ciega, pero no muda, y su condición la hacía balbucear a la nada y remorderse las uñas y saberse sola sin poder escucharse, sin poder saber si las palabras salían de su boca o corrían como trenes dentro de su imaginación» (Ojeda 2017: 14-15).

Frente a la metamorfosis que padecen los espacios físicos en Nefando (al menos desde la perspectiva de la psique alterada de sus protagonistas), los ambientes que se describen en El mago son áreas asépticas (habitaciones de hoteles, restaurantes, salas de espera de peluquerías, etc.) y anónimas, casi unos no-lugares prototípicos; sin embargo, lo que más destaca en el presente enfoque es que estos escenarios se caracterizan, sin exclusión, por un rasgo común: parecen todos estar padeciendo de una especie de proceso metamorfósico, o transfiguración, 
que difumina su estructura, como si se desdibujaran ante la mirada humana y estuvieran creando un aura borrosa que mantiene viva la incertidumbre acerca de su grado de tangiblidad. Los espacios existen, pero parecen intercambiables, como si los eventos pudieran desplazarse de uno a otro, sin que estos cambios logísticos impliquen alguna desestructuración de la lógica. La incertidumbre acerca del ubi nace, en el texto de Aira, como efecto de la volatilización de las coordinadas espaciales, como si el mapa urbano representara una cartografía abstracta, sobreentendiendo unas posibilidades perfectas de sustituciones. Es la sensación que le ocurre al mago, incapaz de encontrar siquiera el salón de actas del congreso, en su propio hotel:

Pensó que le bastaría con buscar, cerca de la puerta de entrada, el cartel del congreso, quizás los folletos del programa de actividades. Pero no encontró nada. Empezaba a alarmarse. Era un poco sobrenatural, como recorrer una ciudad con el mapa de otra, y no darse cuenta nunca del equívoco. De pronto vio con absoluta claridad que iba a pasar la noche solo, y quizás el resto del congreso se realizaba en otra ciudad, hacia la que ya habían partido todos los demás (Aira 2002: 95).

Volveremos sobre el juego de sustituciones, la condición de desorientación y las prácticas sobrenaturales en el tercer apartado de nuestro análisis; antes, nos dedicaremos a examinar de qué manera Nefando organiza su propia estructura temática, en que las invisibilidades autoelegidas e impuestas forman parte de un discurso más amplio centrado en la manifestación y/o represión de los instintos violentos.

\section{Nefando, o fantasmas y otredades virtuales en el territorio de lo abyecto}

La estructura narrativa que Ojeda concibe para su novela se apoya en la presencia de una suerte de investigador oculto: se trata de una voz masculina anónima que interactúa por separado con los personajes que pueblan el piso barcelonés (con exclusión de los tres hermanos Terán, que ya han emprendido el viaje de regreso a su tierra). La razón de los encuentros del anónimo investigador con los habitantes del apartamento reside en realizar un conjunto de entrevistas que le permitan reconstruir ex-post el funcionamiento del juego en línea ideado por los tres hermanos y, sobre todo, comprender las razones que llevaron a su creación. Las condiciones de aislamiento anímico y de (casi) encierro espacial que 
experimentan los Terán a lo largo de la narración puede ofrecer alguna clave de lectura en este sentido: los abusos sexuales, el encierro doméstico y las violencias padecidas durante los años de la infancia en su propia casa se reflejan en la necesidad de una cierta forma de representación de lo acontecido. Para lograr esta conceptualización casi catártica de lo vivido, los hermanos eligen una herramienta tecnológica: un ordenador, como si sintieran que existe una interacción entre la dimensión de lo real y el espacio de la simulación del videojuego. Los tres chicos parecen estar conviviendo con un vacío de sentimientos que no saben cómo llenar: por eso necesitan que la máquina, es decir, el ordenador cree una Otredad (un personaje virtual) en que se reflejen ciertas violencias conocidas, puesto que «allí donde ya no hay nada, debe aparecer el Otro. Ya no estamos en el drama, sino en el psicodrama de la alteridad, de la misma manera que estamos en el de la sociabilidad, de la sexualidad, en el psicodrama del cuerpo y en el melodrama de todo eso a través de los metadiscursos analíticos» (Baudrillard 1999: 135). En este drama contemporáneo de la sociabilidad, de la sexualidad y del cuerpo, la interacción que se crea entre el individuo que empieza a jugar en la pantalla y la máquina no debe entenderse como una nueva forma de intercambio comunicativo, sino como una expresión más de la desaparición de la dimensión social y de la anulación de toda alteridad corpórea.

Se alcanza, así, un estado por el que entre el hombre y la máquina surge un cierto isomorfismo, sin que esto impida que entre ambos se mantenga una «distancia indiferente» Si es cierto que los jugadores en la red tienen la sensación de estar conectados entre sí, no deja de ser una verdad irrefutable el hecho de que esa conexión atañe sólo a las máquinas, las cuales «van más deprisa porque están desconectadas de cualquier alteridad y las redes las juntan como un inmenso cordón umbilical entre una inteligencia y otra inteligencia gemela. Pero en esta homeostasis de lo mismo con lo mismo, la alteridad ha sido confiscada por la máquina» (Baudrillard 1999: 135). La construcción ficcional que plantea Ojeda reúne en sí el motivo de la relación entre el ser humano y la máquina, el del intercambio entre seres humanos alejados físicamente (cuya interacción se da en la red) y el motivo de la violencia extrema como algo innato en el ser humano (una condición que se refleja en las actividades llevadas a cabo en los «canales homeostáticos» de la red). La advertencia presente en Nefando remite a que las formas de expresión de la violencia en la contemporaneidad se han modificado, puesto que se reduce el número de guerras en las que los seres humanos están físicamente involucrados, 
y lo que predomina es la práctica de la violencia virtual, es decir, la que se puede realizar -o simplemente ver- en el cyberespacio ${ }^{5}$. Así, las redes que funcionan como «un inmenso cordón umbilical», a las que alude Baudrillard, representan el nuevo espacio donde la violencia se cultiva:

Todos albergamos un deseo de violencia. La violencia está en el hombre, forma parte de su energía, de su fuerza. [...] Nuestra realidad está cada vez más embebida de cosas que no podemos tocar directamente. Internet es nuestra segunda casa. La mayoría de las cosas que decimos y hacemos no las realizamos con las manos, sino a través de la red, que traslada los datos de un lado al otro, alrededor del mundo. Somos seres humanos, necesitamos sentir la existencia en nuestra propia carne. Ya no hay guerras donde combatir físicamente sino sólo virtualmente: da igual que sean guerras económicas, o guerras en el cyberespacio a través de virus. [...]. Si no puedo más practicar la violencia, al menos necesito verla. Y verla hasta el final, sin censuras (Silenzi 2018: 31-32) .

La novela de Ojeda, en suma, indaga en los procesos de desaparición de lo social y de difuminación de la alteridad y los pone en relación con las nuevas formas de realización y consumo de la violencia. En una estructura conceptual de este tipo, el rol de la voz anónima que desempeña el papel de investigador / entrevistador representa un elemento clave de conexión en el marco de lo humano, es decir, entre los distintos protagonistas del relato. No es secundario observar cómo las entrevistas tienen lugar cuando ya el grupo se ha desmembrado y nadie más vive en el piso: gracias a esta operación de recolección de informaciones a posteriori, el hombre logra reconstruir (junto al lector) fragmentos aislados del pasado de cada uno de los seis jóvenes. Y, sin embargo, la novela presenta un entramado

\footnotetext{
${ }^{5}$ Subrayar la objetiva disminución en el número de guerras en que el ser humano se involucra físicamente no quiere decir que en el mundo contemporáneo estos enfrentamientos hayan desaparecido: basta recordar lo que pasa hoy en día en Libia, Ucrania, Siria, por mencionar solo algunos casos de guerra y otras formas de violencia para nada virtual. Se entiende que la observación de Silenzi encuentra su ámbito de aplicación en ciertas áreas geopolíticas, como Europa occidental y el continente americano.

${ }^{6}$ Así en el original italiano: «Tutti abbiamo voglia di violenza. La violenza è nell'uomo, è parte della sua energia, della sua forza. [...] La nostra realtà è sempre più impastata di cose che non possiamo toccare direttamente. Internet è la nostra seconda casa. La maggior parte delle cose che diciamo e facciamo, non le facciamo con le mani ma attraverso la rete que porta dati qua e là, in giro per il mondo. Siamo uomini, abbiamo bisogno di sentire l'esistenza sulla nostra carne. Non ci sono più guerre da combattere fisicamente ma solo virtualmente, che siano guerre economiche, o guerre nel cyberspazio a colpi di virus. [...] Se non posso più praticare la violenza, almeno ho bisogno di vederla. E vederla fino in fondo, senza censure» [la traducción es mía].
} 
formal más complejo aún, puesto que su estructura en capas superpuestas la acerca a la de un pastiche, en el que se suman unas reflexiones que la propia autora expresa a través de Kiki sobre las dificultades ínsitas en todo proceso de creación: «también hay confesiones, fragmentos de foros de gamers, ilustraciones y personajes que hablan sin intermediarios. Kiki, por ejemplo, se narra a sí misma el proceso de creación de la novela erótica que está escribiendo» (Arenas 2018).

En esta estructura fractal, muchos de los personajes secundarios funcionan como una suerte de marco escénico animado que refleja una condición anímica dominante en el texto, relacionada con la necesidad de desaparecer, de convertirse en sombras silenciosas. Así, por ejemplo, el Cuco Martínez, uno de los seis inquilinos, relata los pormenores de una relación sentimental que mantuvo años atrás con una joven y describe en estos términos a la madre de su pareja de entonces:

La mamá de Lola, por ejemplo, era siempre una sombra. [...] La señora nunca hablaba y, de alguna manera, siempre se las arreglaba para sentarse en el lado de la mesa que menos luz tenía, lo que hacía que apenas pudiera verla. Durante las cenas se convertía en una mancha borrosa y oscura que se movía como si llevara encima de la cabeza una canasta de frutas o algo por el estilo, un peso que la obligaba a mantenerse recta y a no realizar movimientos bruscos. Lo curioso es que Lola y su padre actuaban como si ella no estuviera, lo que hacía que su condición de sombra se acentuara (Ojeda 2017: 19-20).

La presencia de figuras que intentan ocultar su semblante ante la mirada de los demás es un rasgo que está presente también en el segundo plano de la ficción, es decir, en el nivel metanarrativo que relata las vivencias y los accidentes de los personajes de la novela que está redactando Kiki Ortega. Junto a los dos protagonistas principales de la novela, Diego y Eduardo, destaca la figura de la joven Nella: si bien el lector, en las páginas finales del texto, se enterará de que se trata de una adolescente perversa y adicta a la necrozoofilia, no deja de ser llamativa su actitud en el aula, donde la joven adquiere por voluntad propia rasgos casi espectrales, buscando desaparecer o incluso metamorfosearse:

Antes de que los profesores la obligaran a presentarse, ella ya había logrado confundirse con la escenografía y simular su propia ausencia, transparentándose, adquiriendo posturas muy rectas y quietas, respirando igual que las plantas. Diego y Eduardo encontraron irritante su carácter de insecto o de pez de agua dulce [...]. Entonces notaron su condición 
autoelegida de espectro, su rostro lácteo y sus labios gruesos, húmedos, igual que un par de pequeńas lombrices (Ojeda 2017: 114-115).

En otras ocasiones la condición de negación del «yo» (la condición autoelegida de espectro) se aplica a las dinámicas, complejas e irresueltas, de aceptación de la propia identidad; es el caso del ya mencionado Iván Herrera, otro de los seis habitantes del piso barcelonés, quien vive en un estado de obsesión permanente por desvincularse de su propio género sexual. La incomodidad con su propio cuerpo lo lleva a convivir con un estado casi alucinatorio a causa del cual, puesto ante un espejo, desnudo, se percibe como un fantasma: «Te mantuviste firme mientras una canoa se acercaba al puerto llevando consigo un espectro ennegrecido. Sólo pudiste entrever su forma cuando alcanzó la tierra y empezó a caminar hacia ti. Te reconociste en él, el abominable tú, y miraste al espejo sin imagen que llevaba entre las manos, un espejo que emanaba nubes» (Ojeda 2017: 23-24). Obsérvese los cambios que padece el «tú» del texto: en un principio, parece un espectro que sólo rompe con la tradición consolidada de la blancura fantasmal y se vuelve oscuro, pero después acaba convirtiéndose en una entidad «abominable» que provoca rechazo (el «abominable tú») y temor en el joven.

Toda la novela de Ojeda parece construirse como un experimento textual llevado a cabo con los sentimientos más incontrolables de sus personajes, que a su vez son el reflejo de un desajuste concreto en el plano de la realidad social; Nefando enfrenta al lector a una escritura visceral, capaz de poner en relación lo cerebral con las sensaciones corporales, según una línea temático-estética contemporánea por la que «la literatura experimental juega con una materia sutilísima hecha de los humores (en el sentido medieval, de movilizar la bilis, la flema), y si pensamos la escritura como creadora de un campo cognitivo total en el cerebro, de transmisiones entre módulos de sensaciones, la escritura se trataría de una intervención telemática en un medio biofísico» (Oloixarac \& Aponte Alsina 2010: 9192). En este sentido, el clima general de violencia, prevaricación, miedos ocultos o manifiestos, y abuso que domina la novela podría leerse desde el sesgo de una teoría neurobiológica que pone en relación tres ámbitos: el sistema social, el proceso de lectura y el acto de escribir, siendo este último el efecto de la interacción de los primeros dos. Se vendría a crear, así, una suerte de proceso circular en el que las sensaciones vividas en el entorno de referencia y los textos leídos influyen en el proceso de escritura (he aquí la idea de la literatura «necesitada» del mundo) y en sus contenidos, como si hubiese un feedback biofísico continuo. 
En la atmósfera general de horror y espanto que caracteriza ciertas páginas de la novela y que marca el tono general del relato, los rostros de los personajes y las expresiones de sus caras acaban convirtiéndose en marcas identitarias indefinidas, que ya no pueden reflejar la subjetividad individual. La anulación de los signos que reflejan los tratos de identidad del ser humano llega al extremo de que, para los personajes del relato, resulta más fácil reconocer a sus compańeros de facultad viéndolos desde atrás que de frente, como si hubiese una mayor indefinición en los rasgos de la cara que en sus hombros y las identidades individuales se desdibujaran: «tú mirabas las espaldas de tus compańeros y te dabas cuenta de que sólo podrías reconocerlos así, de espaldas, porque sus rostros eran volutas de humo, indefinibles, y sus nucas y hombros, en cambio, tenían nombres y apellidos» (Ojeda 2017: 25). Incluso el mismo funcionamiento del juego en línea ideado por los Terán permanece hasta el final en un estado de indefinición, pues los internautas sólo pueden ver en la pantalla una habitación parcialmente a oscuras en que se encuentra, tumbada en la cama, una mujer desnuda de la que no se sabe si está dormida, narcotizada o muerta. En estos elementos reside el núcleo de la triple narración (la de Ojeda que crea a sus personajes; la de Kiki que crea su propia novela; la de los Terán que crean su videojuego): en la superposición que se realiza entre la fascinación por lo macabro, la muerte, la violencia relacionada con lo sexual y la tecnología. Los abusos y las violaciones que padecen en su infancia los tres hermanos Terán, y su negativa a toda forma de denuncia, remiten no sólo a una estructura conceptual en que se plantea como «naturalmente posible» el sometimiento físico del más débil, sino también a una suerte de aceptación psicológica ex ante de la superioridad de quien abusa, según un modelo que refleja el de las torturas en sistemas represivos. Así lo subraya Jean Franco: «la violación [...] suprime cualquier aserción de la víctima de que se encuentra en la misma categoría humana que el violador, quien confirma su superioridad» (Franco 2016: 114). Sobre la base de esta jerarquía que se establece en el plano anímico entre quien ejerce la violencia y quien la padece, Ojeda logra reflejar en su novela una mezcla de pulsiones: el cuerpo sobre el que se ejerce la violencia es vida y materia inerte, y esto obliga a reflexionar sobre la relación entre el elemento erótico y la dimensión tanática, según un modelo que celebra

el inevitable sex appeal del inorgánico. [...] Esta fusión de orgánico e inorgánico, esta compenetración de carne y materia, este cuerpo-mundo convertido en mercancía, «glamourizado», «pornografiado», convertido en icono mediante símbolos fashion-fetish-fascist masivos y corrosivos. La 
muerte es seductora, la muerte es erótica, se difunde y prolifera, [...] en los más desenfrenados, fantasiosos y perversos orgasmos bélico-sexuales (Palladini 2008: 161) ${ }^{7}$.

La novela de Ojeda es un texto borderline que -a través de un juego enigmático, críptico y terrorífico- indaga en el imaginario biomórfico de la sociedad contemporánea mediante la creación de una «diversión interactiva» que no deja de ser autodegenerativa. Claro que en la novela hay formas distintas de autodegeneración: la anulación del «yo» que se aplica al caso de Kiki Ortega debe desvincularse de la seducción erótica del juego en red y debe entenderse, en cambio, como una sensación de insignificancia que el propio ser humano experimenta como producto de sus fracasos: su conflicto interior permanente consiste en la imposibilidad de redactar su proyecto de novela, en fin, en su incapacidad para «expresarse». Antes de enfrentar el desafío de la escritura, la joven siente que en su mente residen los elementos temáticos y las herramientas para sacar a luz no sólo sensaciones e ideas, sino también a los pequeńos fantasmas que habitan su psique; se encuentra en un estado que, en palabras de Marcel Schwob, caracteriza a la fase previa a la creación y que puede resumirse así: «Imaginemos un ser cuyo cerebro sea atormentado por fantasmas que tengan una tendencia a la realidad, como las imágenes tienen una tendencia alucinatoria, y que, al mismo tiempo, aún no cuente con la voluntad necesaria para actuar o para proyectar sus fantasmas tras haber luchado contra ellos» (Schwob 2006: 68-69). El filósofo francés sostiene que este estado representa una etapa a lo largo de la evolución intelectual de la mayoría de los artistas que han marcado todo proceso creativo del siglo XX. En el caso del personaje femenino de Nefando, su sensación de incapacidad y su estado casi alucinatorio se trasladan a un plano físico, a la dimensión corporal, y este trasvase al nivel tangible hace que la joven se perciba a sí misma como un ser mudo, un cuerpo inerte salpicado de agujeros y totalmente vacío:

Estaba convencida de que podría escribir sobre cualquier cosa si me lo proponía, si me echaba la mano en el corazón de púas y me lo juraba [...]. Creía que tenía mucho que decir, que estaba llena por dentro,

\footnotetext{
${ }^{7}$ Así en el original italiano, en que Palladini se refiere al «indefettibile sex-appeal dell'inorganico. [...] A questa perfusione di organico e inorganico, a questa compenetrazione di carne e materia, a questo corpo-mondo mecificato, "glamourizzato», pornografizzato, iconizzato in simboli fashion-fetish-fascist massivi e corrosivi. La morte è seduttiva, la morte è erotica, dilaga e prolifera [...] nei più sfrenati, fantasiosi e perversi orgasmi bellico-sessuali» [la traducción es mía].
} 
manantializada y lista para llenar la hoja en blanco; pero en realidad escribía para crearme un discurso que no tenía. Yo estaba agujereada y sin lengua. [...] A veces uno tiene la voluntad de decir y luego se da cuenta de que no tiene nada, ni siquiera una idea pequeńa, una expresión fallida de originalidad, que sea digno de pronunciar (Ojeda 2017: 79).

La inconsistencia del ser humano se refleja tanto en la ceguera como en la sensación de sentir su cuerpo vacío, agujereado, como si todavía faltara el último eslabón antes de que los fantasmas interiores puedan ver la luz a través de la creación literaria. Nótese cómo en la descripción del estado anímico de la joven parecen confluir la hermenéutica moderna, con su fe en la palabra en cuanto camino hacia la verdad más absoluta, y el constructivismo con la idea de que toda verdad se construye a través del lenguaje. La crisis de Kiki Ortega surge, en particular, de la falta de coincidencia temporal entre el momento en que se forman, por un lado, el sentido estético personal y la inteligencia, y, por otro, el momento de máximo desarrollo de la voluntad. El resultado creativo surge sólo en el instante en que estas fases coinciden y es en ese instante cuando el producto de la creatividad se colocará entre el artista y el mundo, como un fantasma que desempeńa el rol de filtro entre el creador y la realidad:

La inteligencia y la estética interior se forman mucho antes que la voluntad. Para producir una obra de arte es necesario que la voluntad haya alcanzado su desarrollo. Las creaciones o los fantasmas del artista, puesto que éste aún no puede vislumbrarlos estéticamente, se interpondrán antes entre él y la sociedad, lo aislarán del mundo, o él los introducirá en el universo, como don Quijote, que no posee otra locura que esta (Schwob 2006: 69).

Hasta que llegue ese momento, Kiki experimenta un estado de «inconclusión existencial», sin que exista posibilidad de resolución de su impasse psicológico, puesto que se establece una relación de causa/efecto entre su desarreglo mental y la confusión que se genera en ella, y que la lleva a no poder concluir la escritura de su texto de ficción. Su estado depresivo bien puede ser el factor desencadenante de su sensación de ceguera o de que se perciba a sí misma como un ser agujereado, pero es sobre todo una condición íntimamente ligada a lo «no-logrado» de su escritura. De este estado inconcluso surge su sensación de aniquilación individual y su renuncia a llenar la hoja en blanco, pues «una vez alcanzado un punto crítico de inconclusividad, una vez lograda la figura productiva de lo inconcluso, no tendría sentido prolongar la escritura, y en el vacío dejado por esa (in)conclusión afloraría el deseo de muerte 
original» (Prieto 2016: 175). En el caso concreto de Kiki, lo inconcluso se asocia con un deseo de muerte lato sensu, que se expresa no en una completa autodestrucción, ni en pulsiones masoquistas o de aceptación pasiva de la violencia, sino en la traslación de lo macabro y funéreo a sus contenidos ficcionales.

Para concluir esta sección, cabe detenerse en una última forma de desintegración, esta vez textual: se trata de que, en los apartados finales de la novela, el texto escrito desaparece y deja lugar a unas páginas en que aparecen unos dibujos sencillos, hechos por una mano adolescente, acompañados de algunas breves frases o palabras sueltas. Se aclara que las páginas pertenecen a unos cuadernos de apuntes de la más pequeña de los hermanos Terán, María Cecilia, que realizó esos dibujos y trazó esas palabras con tan sólo catorce años. Ojeda lleva a cabo, así, un proceso de «desestructuración de la integridad del texto», siguiendo una línea estética en la que la iconicidad se suma al texto escrito o, incluso, se coloca en su lugar. Leída en estos términos, la desintegración de la palabra escrita refleja uno de los rasgos más novedosos de la novela contemporánea que:

se presenta caracterizada por una continuidad epistemológica entre la literatura, la imagen, la sociología, el arte, la música, las nuevas tecnologías y la ciencia. [...] El narrador pangeico no distingue límites de influencia, y trabaja indistintamente con esos materiales [...]. [Estas novelas] suponen combinaciones de literatura y música, literatura e imagen, literatura e informática, literatura y arte, o varias a la vez. Todas ellas implican el conocimiento, en ciertos casos muy profundo, de otros saberes y/o ramas artísticas, que se aplican sin solución de continuidad a la hora de la elaboración del texto, entendido este término en un sentido lo suficientemente amplio (Mora 2012: 101-102).

Los dibujos de María Cecilia, al apostar por reclamos visuales que ocupan el lugar, al menos en parte, de la letra escrita, plantean un discurso múltiple que no sólo desestructura la integridad textual, sino que alude a la desintegración de la identidad abusada, a través de la anulación de la palabra.

\section{El mago, o la superposición de realidad, ficción y proyección}

En un ensayo publicado en 1985 en la Revista de occidente bajo el título de «Retorno a lo sublime y lo bello», Iris Murdoch reflexiona sobre los rasgos de la novela moderna (en lengua inglesa y no sólo) e 
identifica dos polos opuestos: señala, por un lado, la inclinación por parte de algunos escritores hacia textos narrativos que intentan explicar algo de la condición humana a partir de un sesgo casi metafísico, y, por otro lado, remarca el interés de otros escritores por una narrativa que analiza de forma casi didáctica la historia y la sociedad del presente de quien escribe. Al plantear esta distinción, la escritora y filósofa irlandesa aclara que en ambos casos su distinción se refiere a la «novela seria», y la define como una forma de escritura que

tiende a uno de estos dos extremos: o bien es un objeto metafísico y hermético que desearía ser un poema y que intenta comunicar, a menudo bajo una forma mítica, una verdad central sobre la condición humana; o bien es una deshilvanada ética periodística, de inspiración documental o posiblemente incluso didáctica, que ofrece un comentario sobre instituciones del momento o sobre algún asunto histórico. Se nos proporcionan cosas o verdades (Murdoch 1985: 44).

Esta bipolaridad de la escritura significa que el escritor del siglo XX se ha visto en la condición, al momento de escribir, de cumplir con ciertas «tareas» que representaban también una forma de límite para su actividad creadora; los grandes narradores del período comprendido entre 1930 y 1980 se imponían, por ejemplo la reconstrucción de la cosmovisión de su propio presente, como si en cada texto fuera necesario recrear ex novo la visión universal de su tiempo histórico de referencia. Otros narradores, sobre todo los del Boom, se dedicaban a la creación de figuras de ficción que fueran «firmes», «identificables» $\mathrm{y}$ «grandes» en su manera - positiva o negativa-de representar al ser humano racional, que se había impuesto en las letras occidentales desde el Siglo de las Luces. Frente a este tipo de literatura, limitada por esas tareas autoimpuestas, en el marco de la literatura en lengua española un conjunto de escritores contemporáneos está proponiendo una suerte de desestructuración de los esquemas de la novela moderna, a través de una arremetida contra los axiomas anquilosados heredados de la tradición. César Aira es, precisamente, uno de estos autores:

la única forma posible de literatura moderna interesante es hoy, como decía Kundera, la antimoderna, aquella que desactiva, irónicamente, sus postulados. Por eso me interesan autores como Bellatin, Fresán o Aira que, con sus aciertos pero sobre todo con sus errores, hacen un inmenso trabajo por la novela futura, a base de socavar la novela moderna, destruir sus cimientos, burlarse de sus reglas añejas y desfasadas, y hacer una 
escritura profundamente deconstructiva, si sabemos entender bien el espíritu de Derrida (Mora 2012: 95).

La destrucción de los cimientos de la novela moderna no debería entenderse, sin embargo, como un verdadero "parricidio», comparable al que llevaron a cabo las vanguardias históricas en los primeros años veinte del siglo pasado: no obstante, está desestructuración a la que alude Mora da cuenta de los cambios en la estructura social y de la pérdida de vigencia de los valores estéticos establecidos. En este marco, El mago, novela publicada en Argentina en 2002, obliga al lector a sumergirse en un espacio de ficción en el que lo mágico se plantea como cifra de la matriz trans-racional y hace que el destinatario del relato se vea forzado a aceptar una continua interferencia en la racionalidad de su propio pensamiento. Existe en el relato una fricción continua entre la lógica del lector, desposeído de poderes mágicos, y la forma de pensar y actuar del protagonista de la ficción, un mago dotado de verdaderos poderes sobrenaturales y no un simple ilusionista o prestidigitador. La estructura de la novela, en suma, colocaría el texto en el ámbito de aquellas obras de ficción que se apoyan en «el mundo utópico de lo mágico, en cuanto instancia trans-racional y práctica trans-semiótica en que colapsan las lógicas de sentido del presente» (Prieto 2016: 155).

Aira plantea para su personaje una condición que lo pone por encima de las fuerzas de las que dispone un ser humano: su protagonista está dotado de una suerte de fuerza demiúrgica, por la cual es capaz de crear de la nada a un nuevo ser por medio de sus poderes mágicos. La razón que empuja al hombre a utilizar su fuerza demiúrgica está vinculada con la necesidad de interacción con la alteridad, es decir, con su personal exigencia de «invención del Otro». Hijo de la edad contemporánea, Hans percibe la otredad como un bien precioso, más necesario aún para un individuo en su condición anímica, que experimenta a diario un estado de alienación y de confusión con respecto a su propia subjetividad. Así, la presencia de unos seres aparecidos en el mundo real gracias a la magia, como un oximorónico «holograma tangible», empieza a ser un bien necesario para el mago, puesto que la alteridad

ha caído bajo la ley del mercado, de la oferta y la demanda. Se ha convertido en un producto escaso. De ahí su extraordinaria cotización en la bolsa de los valores psicológicos, en la bolsa de los valores estructurales. De ahí una simulación intensiva del Otro, deslumbrante en la ciencia ficción, cuyo problema clave sigue siendo: ¿Quién es el otro?,¿Dónde está el otro? Pero 
la ciencia-ficción está hecha a imagen y semejanza de nuestro universo cotidiano, donde reina una especulación desenfrenada y casi un mercado negro de la alteridad y la diferencia (Baudrillard 1999: 135).

En este mercado negro de la alteridad, los poderes del mago, casi sin límites, se convierten en una herramienta para compensar una subjetividad incompleta: «En el caso de una creación ex nihilo [del Otro], las posibilidades se multiplicaban; directamente se hacían demasiadas; la criatura que salía de la galera podía ser cualquier cosa: hombre, mujer, joven, viejo, etc. En cierto modo, la magia era esa proliferación, así que el exceso era inescapable» (Aira 2002: 24). Como consecuencia de estas posibilidades que se multiplican, a lo largo de la novela el lector se ve obligado a convivir con la sensación, incómoda y persistente, de un «caso irresuelto», es decir, con la imposibilidad de discernir si el joven Pedro Susano, encargado de hacer de acompańante al mago durante los días del congreso, es un ser real o sólo la proyección de un ejercicio de magia que el artista argentino ha llevado a cabo. El origen de la incertidumbre del lector reside en la confusión que alberga en el mismo protagonista: tampoco el mago es consciente de si el ser con el que interactúa, un sujeto introvertido y posiblemente enamorado del artista, es una trascendencia fantasmal surgida de sus poderes mágicos o un individuo en carne y hueso:

[El mago] estaba más perdido que nunca, aunque se inclinaba por la hipótesis creacionista. Este joven absurdo debía de existir realmente, pero él lo había puesto a trabajar de guía, como un readymade modificado, dejando que su magia trabajara en automático. [...] Si él lo había inventado, no necesitaba mostrarse cortés, ni inteligente, ni siquiera coherente. «Si soy Dios -pensó- todo me está permitido» (Aira 2002: 52-53).

Este proceso de creación que lleva a cabo el mago permite incluir la novela en el marco de aquellos textos de ficción (muy relacionados con los avances de la tecnología en el siglo XXI) en los que el lenguaje narrativo se construye a partir de la presencia en la trama de simulacros, es decir, de un verosímil cuya existencia es inestable: los universos ficcionales marcados por este rasgo superponen la dimensión de la realidad a la de la simulación, y en el caso concreto de Aira, su narrativa "parece buscar un modo de hacer más real la realidad, televisualizando el verosímil, mediante la disolución del pacto realista» (Montoya Juárez 2013: 197).

Ahora bien, a partir de la invención del «joven absurdo», la novela alcanza su estructura narrativa más completa, que plantea tres niveles de 
actuación: el del escritor, es decir, del propio César Aira que escribe una novela protagonizada por el mago Hans Chans; el del mago, como producto literario de la fantasía del escritor; finalmente, el del joven Pedro, como proyección (posible) de las artes mágicas del mago. La existencia al mismo tiempo de tres planos, es decir, la multiplicación de las dimensiones de la acción, implica una cierta y voluntaria dificultad en el control de las relaciones que se establecen entre el segundo y el tercer plano diegético, entre el autor y su producto ${ }^{8}$. Los aprietos en los que se encuentra el mago, tanto para determinar la consistencia real de Pedro como para establecer determinados patrones relacionales hacia él, remiten a una modalidad temática muy presente en la narrativa contemporánea, marcada por la superposición de planos autoriales. En este sentido, una muestra de la difusión de las «estructuras pluri-niveles» en textos en lengua espańola se observa, en un plano comparativo, en el diálogo que la novela de Aira establece no sólo con los tres niveles vistos en Nefando, sino también con el relato «La Ola», que la joven narradora boliviana Liliana Colanzi incluyó en su recopilación Nuestro mundo muerto (2016). En el cuento de Colanzi se plantea la existencia de tres eslabones, o planos de acción: el de la autora, como individuo en carne y hueso y como mujer; el de su propio «yo» que se separa del cuerpo, se aleja de la materialidad tangible y se coloca en un «espacio otro», casi como si fuera una criatura apartada de su origen físico; finalmente, el tercer grado es el de los personajes creados por este «yo» separado:

De pronto tuve una sensación muy peculiar: me vi viajando en dirección opuesta a la nieve, hacia las nubes, contemplando en lo alto mi propia figura acodada a la ventana en esa noche de invierno. Desde arriba, suspendida en la oscuridad y en el silencio, podía entender los intentos de ese ser de abajo -yo misma- por alcanzar algo que me sobrepasaba, como una antena solitaria que se esfuerza por sintonizar una música lejana y desconocida. Mi antena estaba abierta, centelleante, llamando, y pude ver a los personajes de mis cuentos como lo que en verdad eran: seres que a su vez luchaban a ciegas por llegar hasta mi desde todas las direcciones. Los vi caminando, perdiéndose, viviendo: entregados, en fin, a sus propios asuntos, incluso cuando yo no estaba ahí para escribirlos. [...] Quise hablar con las criaturas, decirles que no se preocuparan, o algo por el estilo, pero

\footnotetext{
${ }^{8}$ A través de la multiplicación y superposición de los planos de la realidad y de la ficción, Aira parece retomar, en cierto sentido, la tradición llevada a la cumbre por Luigi Pirandello en Sei personaggi in cerca d'autore, o Miguel de Unamuno en Niebla: acercar su planteamiento a esta línea conceptual confirmaría que el que se presenta en El mago no es un «parricidio».
} 
sabía que no podían escucharme en medio del alboroto de sus propias vidas ficticias (Colanzi 2016: 34-35).

Importa aquí observar cómo el «yo» del plano intermedio en el texto de Colanzi es consciente de que sus criaturas ficcionales viven una existencia independiente, sin que esta libertad signifique, sin embargo, una verdadera autonomía identitaria. En la novela de Aira, la atmósfera de indefinición que acorrala al mago (y a los lectores) hace que el límite entre el segundo y el tercer nivel (entre el personaje de ficción creado por Aira y la proyección de la fantasía del mago) se desdibuje y cree una ambigüedad en cuanto a la consistencia de quien habita el tercer nivel. Ésta imprecisión de los márgenes fronterizos contribuye a la suspensión deliberada de las certezas que envuelve todo el relato: tanto la indeterminación de los límites como el quiebre de los lindes realidadficción-proyección se hacen manifiestos también en otros apartados del relato. El ejemplo más representativo, sobre todo por su valor como discurso de alcance metafórico, es el que remite a la imagen reflejada por el espejo ante el cual el mago se queda asombrado: el hombre que aparece reflejado es el mismo «yo» y sin embargo es también una individualidad ajena, un Otro cuya distancia del «yo» que mira está definida por marcas tangibles y visibles: el reflejo en el espejo lleva un traje que el protagonista estaba seguro de no haberse puesto al salir del hotel:

Su propio reflejo lo había sumido en una completa perplejidad. Estaba paralizado, mirando una figura igualmente paralizada pero a la que no podía reconocer como suya. Era su cara, su cuerpo, sus manos [...]. Su inmovilidad de fulminado y su expresión atónita. Pero todo eso enfundado en un frac negro, camisa almidonada, plastrón, sombrero de copa de seda, zapatos de charol. Era su traje de escena, su disfraz de mago. [...]. Era real, atrozmente real: eso quería decir que había estado todo el día vestido de mago (Aira 2002: 63-64).

Tanto la sensación de profunda incomodidad anímica que caracteriza a la figura del mago, como su malestar interior encuentran su «espacio de exposición» en los ejercicios de magia que el hombre lleva a cabo en la intimidad de su habitación de hotel: los objetos de uso cotidiano a los que da vida (un cepillo de dientes, un jabón, un desodorante spray, etc.) se convierten en "personajes de materia inerte» que llevan a la escena una suerte de drama, interactuando y conversando entre sí. En sus diálogos, construidos según un modelo de ósmosis que superpone la dimensión humana a la materia inanimada, queda patente una desazón de orden 
metafísico: el desasosiego de quien se sabe perecedero. Las reflexiones trascendentes que surgen del diálogo entre el jabón y el desodorante se vuelven una suerte de discurso metafórico introspectivo que refleja el pensamiento del mago:

- A ustedes por lo menos les quedan los envases. Yo simplemente desaparezco. ¡Si supieran lo que es! Vivo en una continua lepra húmeda que me deforma y deshace. Yo tenía una hermosa rosa tallada arriba, y una palabra latina, Lux. Ahora soy una miserable lengua de gato afilada en los bordes, y pronto voy a ser nada. - No se si no es mejor eso que sentir que uno se va vaciando por dentro. El frasco sigue intacto, pero cada vez más liviano. ¡Es horrendo! (Aira 2002: 79).

Una lectura atenta de las palabras que intercambian esos «personajes de materia inerte» revela como su pesadumbre y zozobra no son simplemente el reflejo de la sensación de angustia metafísica del ser humano, sino también una representación metafórica del desasosiego del «creador vejado», es decir, de la congoja que experimenta todo artista y todo intelectual en el marco sociopolítico de un Estado totalitario. En las palabras pronunciadas por los pequeños actores de plástico o metal a los que el mago ha concedido el don de la vida, se vislumbra la consistencia de un drama cuyo guión remite a las reuniones de los escritores disidentes en un país bajo dictadura. Esos artistas parecen «desinflados, blandos, [...] amargados y desalentados, pero con la llama de la creación todavía encendida. No querían rendirse, a pesar de todo» (Aira 2002: 80-81).

En las páginas finales de la novela, la sensación de amargura y desaliento se traslada del plano de los objetos humanizados al nivel de la conciencia del mago: éste comienza a plantearse una serie de dudas y de preguntas acerca de su propio modus vivendi, en búsqueda de una suerte de salvación anímica que lo aleje de la sensación permanente de soledad, aislado de la intensidad del verdadero sentir humano e incomunicado afectivamente. El hombre llega, incluso, a plantearse la posibilidad de que la muerte sea la única salida posible: esta tétrica conclusión se hace concreta en su mente cuando percibe con claridad que toda acción llevada a cabo hasta ese momento para modificar el rumbo de su vida interior se ha demostrado inútil, a causa de la imposibilidad de un cambio íntimo de su propia actitud vital. El resultado de estas elucubraciones siniestras es que la magia no produce otra cosa sino espectros, como si los seres humanos no fueran nada más que fantasmas, individuos ya muertos incapaces de reconocer su condición espectral: «no era la primera vez 
que se preguntaba si la magia, al fin de cuentas, no sería eso: que todos estuvieran muertos, que todo hubiera terminado, y no se dieran cuenta» (Aira 2002: 106).

En el desenlace, el esquema vital trazado a lo largo de los años por el mago se quiebra y deja lugar a la posibilidad de emprender un nuevo camino existencial y profesional: puesto que no puede desprenderse de sus poderes mágicos, innatos, la solución que el hombre vislumbra no puede residir en abandonar la magia, sino en utilizarla en el campo literario. Hans comprende que hasta ese momento no se había atrevido nunca a usar la magia para modificar sustancialmente la realidad a causa de un miedo ético: el pavor de que su intervención pudiera alterar algo en el «tejido del universo». Sin embargo, justo al final de su estadía en Panamá, como consecuencia de una conversación con tres editores locales a cargo de pequeñas editoriales piratas, el argentino entiende que si el resultado de su magia es un libro, no tiene por qué preocuparse por crearlo gracias a la magia «ya que los libros constituían una realidad aparte. No es que los libros no tuvieran efecto sobre el mundo [...] Pero lo hacían naturalmente, en un proceso que se iniciaba con el lector, y seguía el mismo camino de todos los procesos naturales; nadie sospecharía que había habido magia antes» (Aira 2002: 137). Lo que parece estar afirmando el autor, a través de la decisión del mago, no es la desestructuración del elemento mágico, sino su traslado a otro escenario: el universo de lo mágico, en el que la racionalidad se derrumba, confluye hacia otra forma artística, como si Aira estuviera celebrando el ejercicio de la escritura. Sin embargo, sería ingenuo interpretar el desenlace de la novela como una simple celebración de la práctica de la escritura en sí, y sería más oportuno leerlo como una meditación sobre la búsqueda del mago en su proceso de ordenación de su propia confusión mental: tanto al mago como al personaje de Varamo «les salva de ser auténticos peleles una determinación, y les salva de la enajenación el hecho de que al final encuentren un hilo ordenador de su caos» (Doncel 2002). En la decisión salvífica del mago parece residir una respuesta positiva a ese mundo cada vez más rápido y más ebrio, caracterizado por la reducción o la completa elisión de las distancias, al que aludía Baudrillard. A diferencia de lo que ocurre en Nefando, donde parece que los impulsos positivos presentes en el ser humano se han apaciguado, Hans muestra que los deseos provechosos pueden preservarse: el debilitamiento de sus pulsiones positivas (voluntad, gusto, etc.) no ha desembocado, al final, en la consolidación de las energías violentas (como les ocurre, en cambio, a los miembros del piso barcelonés). 
La exploración de nuevos ámbitos, el intento de poner más adelante ciertas fronteras debe desarrollarse - nos parece decir Aira- a través de una disposición espiritual que, aún sin abandonar la magia (alegoría de ciertos dones naturales), tiende a una racionalización del elemento misterioso y de la componente mágica. Esta racionalización no debe llevar al disgusto íntimo del propio «yo», sino a una liberación de la energía comprimida a través de la voluntad de acción, y no mediante un estado permanente de repugnancia hacia uno mismo y hacia el sistema, que desemboca en la violencia. La desherencia de la que habla Baudrillard no significa liberarse de la energía de cualquier manera, como un exorcismo, sino que debe desembocar en una liberación a través de la voluntad de acción: es posible evitar acceder a las nuevas formas del principio del mal, es posible no acudir a los elementos morbosos y las enfermedades del alma. En contra de todo totalitarismo, la literatura muestra su poder subversivo: el mago teme usar sus poderes mágicos para no incurrir en la violencia, teme ejercer una suerte de abuso del poder, pero a través de las letras sí que acepta «cambiar» el mundo.

La traslación de este discurso al ámbito textual es lo que plantea Aira, en cuya novela se vislumbra una estructura temática capaz de superar definitivamente una cierta tipología de ficción que acude a motivos místicos, esotéricos, a las supersticiones, y juega con

la magia, lo legendario, el milagro, el misterio, el sueńo y -al describir los estados morbosos por las patologías del alma humana [...]- condensa interrogantes y respuestas literarias significativas, busca colmar los vacíos, explorar las nuevas (y replantear las antiguas) fronteras, desbordando límites, instalándose en la muerte misma, complaciéndose en lo excesivo (Phillipps-López 2003: 33).

\section{REFERENCIAS BIBLIOGRÁFICAS}

Aira 2002: César Aira. El mago. Barcelona: Grupo editorial Random House Mondadori.

Arenas 2018: Isabel Cristina Arenas. «Nefando: gritos de silencio». El espectador, Bogotá, 15 de febrero de 2018.

Baudrillard 1999: Jean Baudrillard. La transparencia del mal. Ensayo sobre los fenómenos extremos. Barcelona: Editorial Anagrama.

Colanzi 2016: Lilia Ana Colanzi. Nuestro mundo muerto. Ciudad de México: Almadía Ediciones. 
Doncel 2002: Diego Doncel. «El mago, de César Aira». El cultural, Madrid, 10 de julio de 2002.

Franco 2016: Jean Franco. Una modernidad cruel. Ciudad de México: Fondo de Cultura Económica.

Fresán 2017: Rodrigo Fresán. La velocidad de las cosas. Barcelona: Penguin Random House Mondadori.

López 2016: Ignacio López. «Nefando, un libro de Mónica Ojeda. ¿Hay palabras para todo el silencio que vendrá?». Verboten Mgazine, 14 de diciembre de 2016.

Montoya Juárez 2013: Jesús Montoya Juárez. Narrativas del simulacro: video cultura, tecnología y literatura en Argentina y Uruguay. Murcia: Editum, Ediciones de la universidad de Murcia.

Mora 2012: Vicente Luis Mora. El lectoespectador. Deslizamientos entre literatura e imagen. Barcelona: Editorial Seix Barral.

Murdoch 1985: Iris Murdoch. «Retorno a lo sublime y lo bello». Revista de occidente, 44/I: 39-46.

Negroni 2009: María Negroni. Galería fantástica. Buenos Aires: Siglo XXI editores.

Noguerol Jiménez 2018: Francisca Noguerol Jiménez. «Escrituras contemporáneas en español». Revista Landa, 7/1: 122-130.

Ojeda 2017: Mónica Ojeda. Nefando. Barcelona: Editorial Candaya.

Oloixarac \& Aponte Alsina 2010: Pola Oloixarac \& Marta Aponte Alsina. «La reflexión literaria». Paz Balmaceda (ed.). 18 escritores. La novela latinoamericana contemporánea. Barcelona: ediciones Barataria, 77-117.

Palladini 2008: Marco Palladini. «Derive imperfette di letteratura portatile a futura memoria». Cesare Milanese (ed.), La letteratura nell'era dell'informatica. Proposte per il XXI secolo. Milano / Roma: Francesco Bevivino Editore, 147-174.

Phillipps-López 2003: Dolores Phillipps-López. «Introducción». Cuentos fantásticos modernistas de Hispanoamérica. Madrid: Cátedra, 9-47.

Prieto 2016: Julio Prieto. La escritura errante. Illegibilidad y políticas del estilo en Latinoamérica. Madrid: Iberoamericana-Vervuert.

Schwob 2006: Marcel Schwob. El terror y la piedad. Buenos Aires: Libros del zorzal.

Silenzi 2018: Michele Silenzi. Mover. Odissea contemporanea. Milano: Edizioni Il Foglio. 


\section{FORMS OF INVISIBILITY IN TWO LATIN AMERICAN NOVELS FROM THE BEGINNING OF THE NEW CENTURY. SELF-SELECTED TRANSPARENCIES, CYBER-MONSTERS AND CORPOREAL HOLOGRAMS IN MÓNICA OJEDA AND CÉSAR AIRA}

\section{Summary}

The purpose of the present essay is to study in what way some idiosyncratic features of contemporary life (the weakening of positive human impulses, the consolidation of the violent energies of repulsion and hostility towards the Other, the rejection of sociopolitical systems, etc.) are transferred to the literary field in two fiction texts written in the first years of the 21st century. On the basis of reflections by theorists such as Jean Baudrillard, Marcel Schwob and Jean Franco, among others, we will try to analyze both the relationship established between the liberation of the vital energy present in the human being and the exercise of evil, as well as the way in which contemporary fiction expresses this contamination. Object of study are two short novels: Nefando (2017), by the Ecuadorian writer Mónica Ojeda, and El mago (2002), by the Argentine César Aira. Our analysis tries to highlight the presence Żin both textsŻ of two characteristic tendencies of the most recent Latin American literary production: on the one hand, the link between the manifestations of extreme violence and a certain type of fiction texts that adopt fragmentary structures, include images or drawings in the texts, show the most sordid and evil of the interaction between human beings (Ojeda). On the other hand, we will try to demonstrate how certain literary products manage to express the alterations of the real in function of the magical, and focus on the representation of states of alienation of the subject with respect to his own subjectivity (Aira).

Keywords: Latin American Literature of XXI Century, Mónica Ojeda, César Aira, Nefando, El mago. 